\title{
A Business Performance Management Framework
}

\author{
Ana Carina Brissos Pereira and Miguel de Castro Neto \\ NOVA Information Management School (NOVA IMS), Universidade Nova de Lisboa, \\ Portugal \\ m2016151@novaims.unl.pt, mneto@novaims.unl.pt
}

This is the Author Peer Reviewed version of the following conference paper published by Springer:

Pereira, A. C. B., \& de Castro Neto, M. (2020). A Business Performance Management Framework. In Á. Rocha, H. Adeli, L. P. Reis, S. Costanzo, I. Orovic, \& F. Moreira (Eds.), Trends and Innovations in Information Systems and Technologies: WorldCIST 2020 (Vol. 1, pp. 312-323). (Advances in Intelligent Systems and Computing; Vol. 1159 AISC). Springer. https://doi.org/10.1007/978-3-030-45688-7_32

\section{(@) $(1) \Theta$}

This work is licensed under a Creative Commons Attribution-NonCommercial 4.0 International License. 


\title{
A Business Performance Management Framework
}

\author{
Ana Carina Brissos Pereira and Miguel de Castro Neto \\ NOVA Information Management School (NOVA IMS), Universidade Nova de Lisboa, \\ Portugal \\ m2016151@novaims.unl.pt, mneto@novaims.unl.pt
}

\begin{abstract}
In an increasingly competitive market, companies need to look not only at results, but also at how they can improve their performance to achieve them. Knowing the factors that influence business performance allows to identify initiatives that lead to their improvement or mitigate potential risks, ensuring strategic alignment across the organization. This article presents a Business Performance Management (BPM) framework, where the key components that impact business performance are described, which includes Business Intelligence (BI) as an integral part of the technological framework and a Performance Management (PM) cycle as a methodological approach to its implementation for business performance improvement.
\end{abstract}

Keywords: Business Performance Management, Business Intelligence, Framework

\section{Introduction}

The successful execution of a business strategy is a well-recognized requirement for an organization's survival in the hypercompetitive marketplace [1]. BPM becomes essential in allowing companies to align operational strategy and objectives with business activities in order to manage overall performance through better supported actions and decision making [2].

BPM is a set of integrated closed-loop management and analytic processes supported by technology that helps businesses define strategic goals, measure and monitor its Key Performance Indicators (KPI) and act proactively to achieve goals [1]. BPM can also be referred to as Enterprise Performance Management (EPM), Corporate Performance Management (CPM), Strategic Enterprise Management (SEM) and, in a simplified version, Performance Management (PM). Note that some organizations use the acronym BPM for Business Process Management which, although related to PM, is a distinct concept which is not within the scope of this article.

This article focuses on a BPM framework presentation where the key components that impact business performance are described, which includes BI as an integral part of the technological framework and a PM cycle as a methodological approach to its implementation for business performance improvement. 


\section{Business Performance Management}

BPM involves a variety of integrated operational and analytical processes that complete two sequential activities: First, it facilitates the creation of strategic objectives by defining concrete objectives and meaningful KPIs for the organization; the second, supports the next phase of performance management, where objectives are related to operational metrics and linked to performance actions or initiatives that lead to effective strategy execution [3]. BPM is about improving performance in the right direction [4], allowing the organization to focus on what really creates business value while ensuring its long-term continuity. BPM encourages process efficiency as well as the efficient use of both financial, human and material resources [5].

\subsection{Business Intelligence}

The concept of BPM becomes inseparable from another important concept that is Business Intelligence (BI) as an integral part of a BPM system.

Business Intelligence (BI) is the process of collecting enough of the right information and in the right manner at the right time and delivering the right results to the right people for decision-making purposes [6]. In other words, BI encompasses a set of procedures, techniques, methodologies and technological tools that allow data collection from various systems (internal and external), processing them for analysis and availability of information in reports and dashboards, which support decision-making and business strategy definition. BI can be defined as the process of transforming data into information and information into knowledge [5]. The main components of a BI architecture are: data sources, ETL processes, data warehouse (DW), On-line Analytical Processing (OLAP) and metadata.

Data sources can be operating and transactional systems such as Enterprise Resource Planning (ERP) - Online Transaction Processing (OLTP) - external sources or data in other BI/DW architectures. These can be structured data in relational databases (DB), or other format such as excel or flat/text files (e.g. csv or txt files), semi-structured or unstructured data such as text documents, PDFs, images, videos, audio or other information that is not clearly organized (or in table format) and cannot be automatically related to other information.

ETL Processes includes three processes: 1) Extract data is the process of identifying relevant data to be collected, which may be either inside or outside the organization and is usually not integrated, is incomplete or duplicate [7]. This data is sent to a temporary workspace called Staging Area (SA), which is never accessible to users.; 2) Transform and cleaning is performed in SA and aims to make the data related to each other, standardizing them through the application of business rules, correcting errors to ensure consistency across the organization for reporting purposes and analysis; 3 ) Load data into the final DW, the presentation layer, is the last phase of the process where data is already uniformed to be consistently presented and accessible for reporting and analysis.

The final DW or presentation area is one of the key components of a BI architecture and is where data is organized, stored and accessible to users for querying, reporting and analysis. This presentation area includes data marts (DM), which are subsets of the 
main DW that aim to meet the specific needs of a specific area (or users) of the organization. The final DW supports next component through data storage and maintenance in multi-dimensional structures for query, reporting and analysis [7].

On-line Analytical Processing (OLAP) is the data access component where data is shared by "OLAP cubes", which allows data exploration, summarized and/or aggregate views from many perspectives in a user-friendly way with fast response time. Data cubes are dimensional models stored in multi-dimensional OLAP structures [7].

Metadata is a very important component which refers to data about data [7]. This area is like a DW encyclopedia [8]. The metadata repository is used to store business and technical information about data, including business rules and data definitions. Ensuring maintenance and regularly updating metadata is essential [7].

\section{The BPM Framework}

The proposed BPM framework rests on five key-components: Environment, Organizational Culture, Systems and Information Technology, Processes and, in the center of everything, People - the cuore (heart) of an organization (see Fig. 1.)

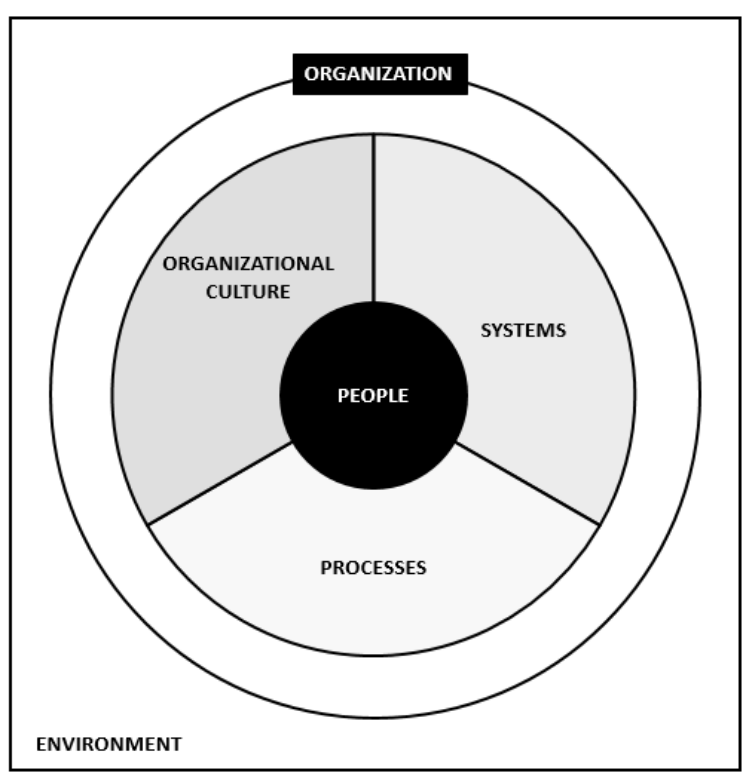

Fig. 1. The BPM Framework

\subsection{Environment}

The environment, or context in which the organization operates, includes all the forces or institutions surrounding the company that may affect performance, operation and resources and directly shape the organizational structure [9]. 
External factors that influence performance may be political (P), economic (E), socio-cultural (S), and technological (T). PEST analysis can be used to analyze the current and future environment as a process of strategic business management [10].

Political factors include governmental, fiscal, labor, commercial, environmental, market regulatory legislation in which the organization operates and other standards, as well as political activities designed to influence its performance [9]. (e.g., European General Data Protection Regulation (GDPR), new accounting standards, fiscal and regulatory policies)

Economic factors represent the overall economic health of the country or region where the organization operates [9]. (e.g., inflation rate, unemployment rate, interest rate, exchange rates)

Socio-cultural factors represent the demographic characteristics, norms, customs and values of the population of the country, region or location where the organization operates. (e.g., population density, population age, education, geographical distribution)

Technological factors include scientific and technological advances in a specific industry, as well as in society in a broader way, and which generate competitive advantage or disadvantage. (e.g., digital cameras, smartphones with integrated camera, Wi-Fi technology, Internet, Internet of Things (IoT), process automation and digitalization)

These external factors create tensions and can constitute threats but also opportunities [11]. In the operational environment, there is also the influence of customers, suppliers, shareholders and the competitive market on the organization's performance.

\subsection{Organizational Culture}

Organizational Culture is the organization's DNA that inspires the people who are part of it, both in the way they think, behave and act, determining the motivation behind their actions [12], impacting individual performance, then the performance of an organization [13]. The organization's DNA includes Vision, Mission and Values.

Vision is what the organization wants and aims to achieve. It is the "future state", the projection of itself in a short, medium and long-term perspective. It's the answer to the question, "Where does the organization want to go?".

Mission is the reason for the organization's existence, its purpose. It is the answer to "Why does the organization exist?".

Values are the philosophy behind people's behaviors and attitudes that lead the organization to fulfill its vision and mission. It includes the beliefs, assumptions, ethical principles and a whole set of understandings that lead people to action, impacting the performance of the organization. It answers the question "How will we achieve the vision and mission?".

Therefore, Vision, Mission and Values are the basis of everything. It is the foundations, structures and pillars that underpin an entire organization, as in a house. If they are not solid, consistent and coherent, they can cause a collapse of an entire organization. Probably the organization will not resist both internal and external pressures and its continuity and economic viability is questioned. 
Also, within this component an increasingly agile culture must be created [14] and foster a performance-oriented culture, continuous improvement with knowledge sharing and transparent communication. An "agile organization" is an organization that has the ability to reinvent, adapt and quickly implement changes and succeed in a turbulent, ambiguous and fast changing context. The type of organizational structure has an impact on the "agility" of the organization, being more agile the lower the hierarchy, the greater the effectiveness of strategic alignment [15]. An Agile organization stands out for both stability and dynamism, and according to a McKinsey \& Company study, less than $25 \%$ of organizations achieve both.

Communicating results, vision, mission and values are critical to strategic alignment. People will only know where to go if they know what the organization's goals and plans are and what is expected of them and how they will contribute to achieving those results.

\subsection{Systems and Information Technology}

The Systems and Information Technology component includes business support infrastructures, architectures, applications and software (such as ERPs, CRMs, etc.), but also BI systems and architectures that feed the BPM system (seen here as a DW architecture exclusively dedicated to BPM). A Technological Framework of a BPM System is presented below (see Fig. 2.).

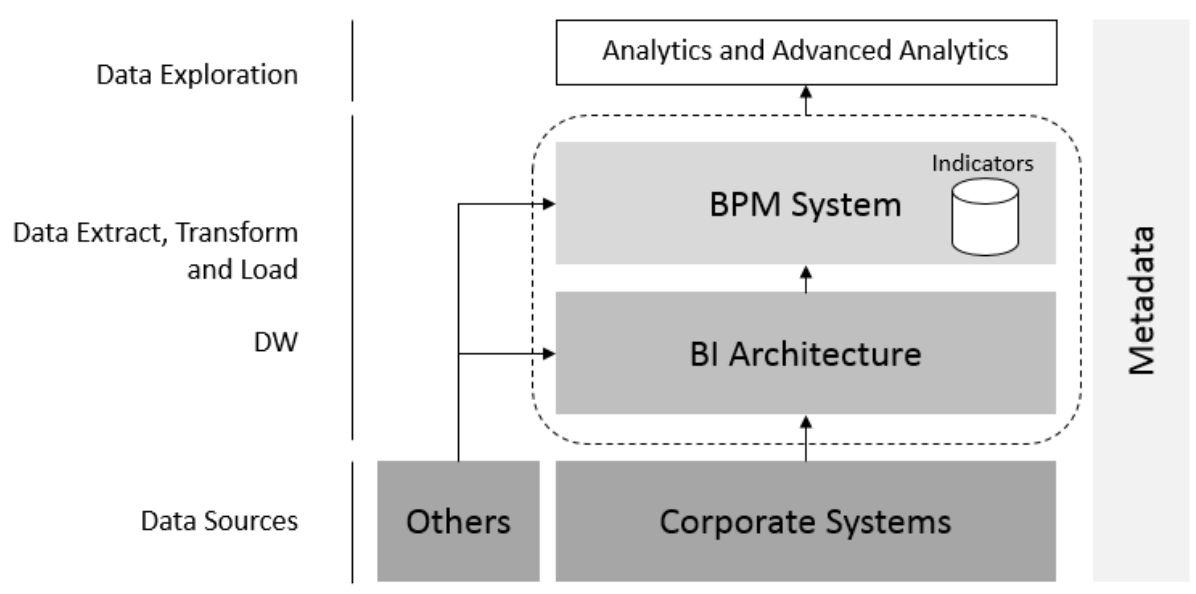

Fig. 2. Technological Framework of a BPM System

The Technological Framework of a BPM System consists of a traditional BI architecture that includes the following subcomponents (see Table 1.): 
Table 1. The subcomponents of the Technological Framework of a BPM System

\begin{tabular}{lcl}
\hline \multicolumn{1}{c}{ Subcomponent } & Area / Layer & \multicolumn{1}{c}{ Examples } \\
\hline Corporate Systems & Data Sources & $\begin{array}{l}\text { Sistemas OLTP, e.g.: SAP ERP, CRMs, Ticketing } \\
\text { Platforms, etc.. }\end{array}$ \\
\hline Other sources & Data Sources & $\begin{array}{l}\text { Excel or flat/text files with manual inputs or indica- } \\
\text { tors/data, survey results, web pages, conversion } \\
\text { rates from external sources, etc.. }\end{array}$ \\
\hline $\begin{array}{l}\text { BI Architecture } \\
\text { (DW or Data Lake) }\end{array}$ & BI Solution & $\begin{array}{l}\text { ETL Processes, Staging Area (SA), Data Ware- } \\
\text { houses, Data Marts or Data Lakes. }\end{array}$ \\
\hline BPM System (DW) & BI Solution & $\begin{array}{l}\text { ETL Processes, exclusive DW for BPM and Perfor- } \\
\text { mance Indicators DB; Indicators Master Data Man- } \\
\text { agement. }\end{array}$ \\
\hline Analytics and & BI Solution, & $\begin{array}{l}\text { Dashboards, queries and ad-hoc reports, Balanced } \\
\text { Scorecards (BSC) and maps, predictive models and } \\
\text { others. } \\
\text { Advanced Analytics }\end{array}$ \\
Analytics & SAS Miner, SAS Guide and others. \\
\hline Metadata & Metadata & $\begin{array}{l}\text { Knowledge Management layer with data about data, } \\
\text { that includes tables and fields description, the } \\
\text { source and metrics formulas, etc.. }\end{array}$ \\
\hline
\end{tabular}

To highlight in this technological framework:

- The importance of metadata as the "knowledge management layer" of all information (organizational assets), from data source systems to their availability in reports and dashboards. This area ensures asset continuity (information/data and architecture) and the maximization of Return on Investment (ROI), hence the importance of being always up to date;

- The data architecture exclusively dedicated to BPM supports activities of the areas responsible for preparing information to support decision-making and performance management, as well as the entire PM cycle;

- The main objective of the performance indicators DB is to store the current and historical values of all metrics considered relevant to the business and to monitor their performance, with the possibility of simulating various scenarios, as well as ensuring the consistency of reported information. Another benefit is the possibility that, in the medium term, it will allow for deeper analysis of pattern discovery and correlations between variables (the metrics) and the development of predictive models, which may bring new knowledge and/or new business insights. Parmenter (2010), refers to the need to create DB to record/store in order to guarantee the reliability and consistency of the reported information [16]. Depending on the organization's technology maturity level and even the size itself, this record could be carried out using common tools such as Ms Excel, Ms Access DB or SharePoint. The important thing is to measure and store the indicators values allowing the 
comparison over time and evaluate the company's performance and strategy execution success.

\subsection{Processes}

The Processes component includes all the business processes of an organization in various areas, such as accounting, logistics, sales, etc., including IT processes, information management and data governance model, as well as PM and decision-making processes. This component has a large scope that is not the focus of this article, however it is important to highlight the relevance of processes simplification, standardization, automation and digitalization combined with an agile, performance-driven and continuous improvement culture.

\subsection{People}

People are the key resource of an organization and without them an organization does not exist or work [10]. Being the most valuable asset of an organization, the people component is the heart of an entire BPM System and it is extremely important to define a Human Resources Management (HRM) strategy integrated into the business strategy that enables the organization to achieve their goals [17].

An organization's DNA is made by the people who are part of it, so People and Organizational Culture are two inseparable components. BPM involves, beyond the communication of the vision, mission and values, and business strategy and objectives, a HRM strategy that promotes the improvement of individual performance across the organization through:

1) Greater involvement and people commitment to the organization through the DNA sharing, which gives them clear direction, alignment and understanding and a sense of purpose, giving meaning to performing their tasks [12];

2) Consistent leadership practices throughout the organization and behaviors that reflect their DNA, ensuring honest and sincere communication, discipline and commitment from leaders, creating trust environment [12]; The leader has an increasingly active role in employee development by becoming a leader-coach;

3) Developing leaders by empowering them with the skills needed for their role consisting of physical, intellectual, emotional and spiritual strength that drives personal fulfillment and in turn inspires others to follow [18];

4) Encourage positive behaviors through leaders at various levels of the organization in order to generate greater enthusiasm and motivation and to gain greater involvement and commitment from employees, encouraging them to consistent positive behaviors and ways of working;

5) Attracting talent to the market and/or university community through good projection of the organization's brand as an employer [19] and presentation of "magnetic" offers for an Employee Value Proposition (EVP) stronger than the competitors [20];

6) Talent retention through fair performance (meritocracy) and training plans that enable skills development and encourage the talent. Promote development opportunities and in a consistent way recognize and reward the performance of both individuals 
and teams, promoting alignment of expectations between employees and the organization [12];

7) Measures allowing family-work balance, such as time flexibility, teleworking (distance work), reimbursement of well-being expenses, employee assistance program (among others), which promote employee well-being and happiness, contributing to higher motivational levels. The role of leaders is critical to the success of policies and measures by encouraging their adoption and/or sharing work tasks to support those who use them [21]. Employee happiness and health become a competitive advantage;

8) Involvement of employees in the community, extending the scope of the organization actions through volunteer initiatives [13].

To highlight, creating a performance culture is finding a balance between performance and people, without sacrificing either [12].

\section{The BPM Spiral}

All components previously described actively participate in the four steps PM cycle, which begins with (1) Strategize - Strategy definition and alignment; (2) Plan - Strategy execution planning; (3) Monitor/Analyze - KPIs and metrics monitoring and analysis; and (4) Act/Adjust - actions and initiatives to correct and/or adjust for goals' achievement. This cycle is executed not in a continuous "closed-loop" (as proposed by BPM standards group [22]), but in a continuous "spiral", recalling Nonaka's (1991) "Spiral of Knowledge". This means that at the end of the first full cycle, the organization and its components have a higher level of knowledge about their performance, allowing them to know the "state of things" more broadly compared to the beginning of the cycle. The BPM Spiral becomes a methodological approach for a BPM System implementation and a process for business performance improvement. Therefore, the concept of "BPM Spiral" and its analogy with Nonaka's (1991) SECI Model [23] is born (see Fig. 3.).

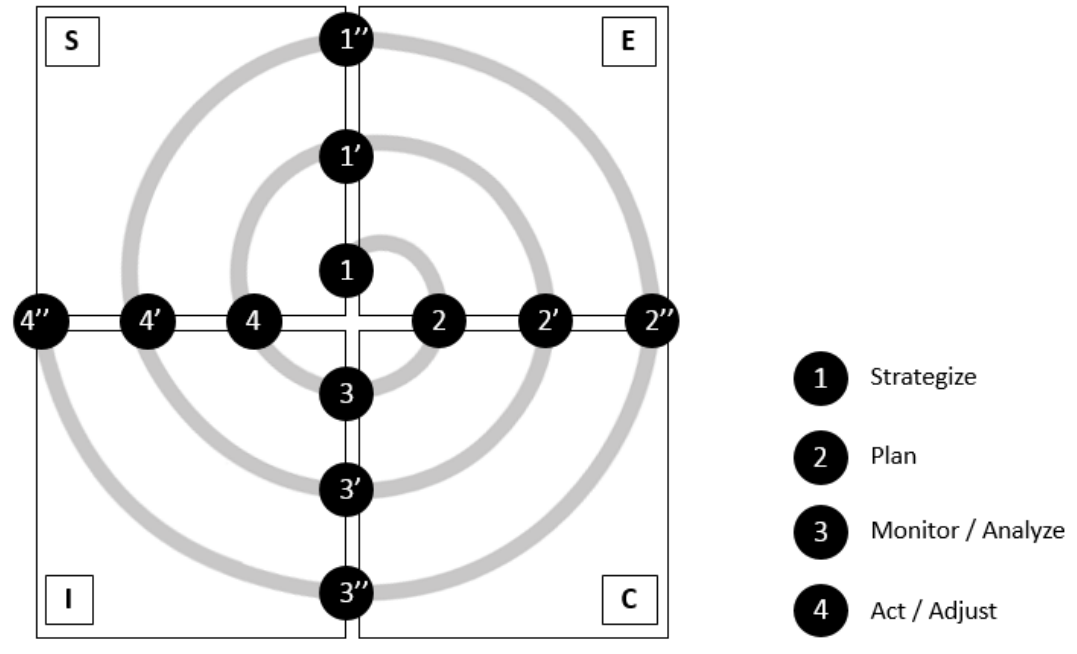


Fig. 3. The BPM Spiral

Briefly, tacit knowledge is what is in people's minds and is created by personal and professional experiences, personal beliefs and perspectives; Explicit knowledge is knowledge described in procedures, manuals and other forms that allow summarizing and mapping information, making it easier to communicate and share [23].

The strategy definition (1') arises from socialization [S], where tacit knowledge of the interaction of previous knowledge level of the spiral (4) is converted into new tacit knowledge, through observation, social interaction with shared experiences, that generate strategic thinking, which results in its definition or redefinition/adjustment. 'Strategize' step wants to answer the question "Where do we want to go?".

Execution planning (2') consists in the conversion of tacit to explicit knowledge through the externalization [E] of the strategy (or its adjustment), which is translated into plans, actions and initiatives to be carried out, budgets definition, objectives and clear goals that are communicated and shared (articulation) through BSC, reports and dashboards and other maps. Plan wants to answer the question "How did we get there?".

In monitoring and analysis (3'), there is the conversion of explicit into explicit knowledge through the combination [C], which involves the collection of internal and external information to the organization in different types/formats, which are converted into new knowledge by interpretation and news insights generation. As an example, we have the KPIs monitoring and the exploration of the "root causes" that lead to the information cross-checking to interpret and to reach conclusions. Monitor/Analyze wants to answer the question "What are we doing?".

Acting and adjusting (4') transforms explicit into tacit knowledge through internalization [I], "learning by doing", which creates new knowledge through the formulation of new know-how and new mental maps on a given subject which leads to goals achievement and strategy success. Act/Adjust wants to answer the question "What do we need to do differently?".

This process from 1' to 4 ' is repeated in new interactions (1" to 4" and so on) without having a specific starting point through organizational interaction by the four patterns. The Tacit-Explicit (externalization/articulation) and Explicit-Tacit (internalization) patterns are important because they require a personal commitment from those who participate, since everything that involves tacit knowledge includes mental models and perceptions that are not easy to articulate and are highly subjective and dependent on individuals [23]. BPM Spiral and its analogy with Nonaka's SECI Model [23] is presented below (see Table 2.) 
Table 2. BPM Spiral and Nonaka's SECI Model [23]

\begin{tabular}{|c|c|c|c|}
\hline Spiral Step & Knowledge Type & Conversion by & Example \\
\hline Strategize & Tacit - Tacit & Socialization & $\begin{array}{l}\text { Boards members meeting for } \\
\text { strategy discussion. }\end{array}$ \\
\hline Plan & Tacit - Explicit & Externalization & $\begin{array}{l}\text { Business plan and budget defi- } \\
\text { nition, objectives, indicators, } \\
\text { metrics and goals definitions, } \\
\text { actions and initiatives and dis- } \\
\text { closure through internal com- } \\
\text { munication channels. }\end{array}$ \\
\hline Monitor / Analyze & Explicit-Explicit & Combination & $\begin{array}{l}\text { Monthly/quarterly indicators } \\
\text { monitoring and analysis } \\
\text { through dashboards or maps, } \\
\text { data exploration and pattern } \\
\text { analysis. }\end{array}$ \\
\hline Act / Adjust & Explicit - Tacit & Internalization & $\begin{array}{l}\text { KPIs interpretation and insight } \\
\text { generations, actions in order to } \\
\text { improve performance and } \\
\text { achieve the goals. }\end{array}$ \\
\hline
\end{tabular}

\section{Conclusions}

The BPM framework proposed in this paper draws on the existent literature, but also on personal observations and professional experience about business performance. A BPM System includes five key-components: Environment, or context in which the organization operates, Organizational Culture, Systems and Information Technology, Processes and People.

A BPM System is much broader transcending organization's boundaries and includes not only internal but also external factors that directly and indirectly impact business performance. PEST analysis - Political, Economic, Socio-cultural and Technological factors - helps organizations to identify threats but also opportunities in the environment that surround the organization which it is part of.

Organizational culture plays a crucial role in individual performance, as well as organizational performance, inspiring people in the way they behave and act in their daily lives. Organization's DNA - Vision, Mission and Values - must be consistent with what is observed in practice and the leaders should be a mirror of this DNA, ensuring honest and sincere communication. Inconsistencies have an impact on individual performance, business and how the organization is perceived by its employees, customers and other stakeholders. An agile organization involves, besides the organizational structure simplification, the ability to adapt systems and processes in order to act quickly and effectively, addressing the new market and customer's needs. Therefore, it's important to foster a performance-oriented culture, continuous improvement and knowledge sharing. 
Systems and Information Technology becomes crucial in monitoring and analyzing business performance, enabling problems anticipation, patterns discovery and variables correlation, among others. An exclusive DW area for BPM that feeds reports and dashboards, allows the recording and storage of indicator values, scenarios simulation and ensures the consistency of reported information. BI is the technological component that integrates a BPM system and supports the "BPM Spiral" processes, allowing the consolidation and treatment of high data volume and its availability for decision-making. On the other hand, BPM uses and leverages BI by adding context and direction, enabling the maximization of ROI for such projects.

The "BPM Spiral" is the process of PM that begins with strategy definition and alignment, its translation into plans, monitoring and analysis and the action and/or adjustment towards the goals' achievement. At the end of each complete cycle, the organization has a higher level of knowledge about its performance.

Finally, people are the cuore (heart) of an organization, the main asset and muscle that drives business performance. People's happiness and well-being become a competitive advantage, generating more motivation and enthusiasm, which in turn increase productivity, improving individual and business performance.

In order to continue the development of the presented BPM framework, in-depth studies should be carried out on each of the components, namely the processes component that was out of the scope of this paper. As part of the methodological approach for the BPM system implementation, a checklist to gather information about the "state of the art" should be developed to identify the components to be created or enhanced for business performance improvement.

\section{References}

[1] M. N. Frolick and T. R. Ariyachandra, "Business Performance Management: One Truth,” Inf. Syst. Manag., vol. 23, no. 1, pp. 41-48, 2006.

[2] C. Ballard and S. Mcdowell, "Business Performance Management meets Business Intelligence," IBM Redbooks, p. 224, 2005.

[3] C. Iervolino, "Business Performance Management," pp. 2-3, 2005.

[4] W. Eckerson, "Best Practices in Management: Business Performance Management and Technical Strategies," TDWI Rep. Ser., no. March, p. 32, 2004.

[5] M. Golfarelli, S. Rizzi, and I. Cella, "Beyond data warehousing," in Proceedings of the 7th ACM international workshop on Data warehousing and OLAP - DOLAP'04, 2005, p. 1.

[6] L. Zeng, L. Li, and L. Duan, "Business intelligence in enterprise computing environment," Inf. Technol. Manag., vol. 13, no. 4, pp. 297-310, 2012.

[7] I. Ong, P. Siew, and S. Wong, "A Five-Layered Business Intelligence Architecture," Commun. IBIMA, pp. 1-11, 2011.

[8] R. Kimball and M. Ross, "The data warehouse toolkit: the complete guide to dimensional modelling," Career Data Anal., no. 978, pp. 1-447, 2002.

[9] R. Daft, Management. 2012.

[10] I. Worthington and C. Britton, The Business Environment. 2006. 
[11] P. Smith, Business Performance Management - approaches and tensions. ICAEW, 2015.

[12] Thomas Deger, "Global Changemaker - Shaping Effective Organizations," Global Changemaker, 2010. [Online]. Available: https://www.globalchangemaker.com/.

[13] G. Cokins, "Performance Management: Integrating Strategy Exectution, Methodologies, Risk, and Analytics," 2009.

[14] McKinsey \& Company, "How to create an agile organization," McKinsey Co., no. October, pp. 1-16, 2017.

[15] K. Aghina,Wouter; De Smet, Aaron; Weerda, "Agility: It rhymes with stability | McKinsey \& Company,” McKinsey Quarterly. 2015.

[16] D. Parmenter, Key Performance Indicators ( KPI ). 2010.

[17] M. Armstrong, Strategic Human Resource Management : A Guide to Action, vol. 16, no. 3. 2006.

[18] J. Barsh, S. Cranston, and A. R. Craske, "Centered leadership: How talented women thrive in career," McKinsey Q., vol. 4, pp. 35-48, 2008.

[19] M. Dewhurst, M. Pettigrew, R. Srinivasan, and V. Choudhary, "How multinationals can attract the talent they need," McKinsey Q., no. 3, pp. 92-99, 2012.

[20] S. Keller and M. Meaney, "Attracting and retaining the right talent," McKinsey Co. Artic., no. November, pp. 1-14, 2017.

[21] M. Pina e Cunha et al., "Desafios à conciliação família-trabalho," Nov. SBE, Confed. Empres. Port., p. 72, 2018.

[22] B. S. Group, "Industry Framework Document," BPM Stand. Gr., 2005.

[23] I. Nonaka and H. Takeuchi, "Knowledge-creating company.," Bloom. Bus. Libr. - Manag. Libr., p. 43, 2007. 